\title{
Muscular dystrophy in man: biochemical aspects
}

\section{By R. J. Pennington, Department of Clinical Chemistry, King's College (University of Durham) and Royal Victoria Infirmary, Newcastle upon Tyne}

The salient features of human muscular dystrophy are that it involves extensive wasting of certain voluntary muscles, that it does not appear to be caused by any lesion in the nervous system, and that it is a hereditary disease. Since the various types have different modes of inheritance, it seems likely that the ultimate cause may be different in each type. The histological changes in the affected muscle have many features in common with muscle atrophy resulting from other causes; some characteristic differences exist, however. It is to be expected that muscle degeneration per se will lead to extensive biochemical changes in the muscle tissue and probably also in the blood and urine. Such changes could conceivably have repercussions on the metabolism of other tissues. Biochemical studies on muscular dystrophy should be seen against this background.

As outlined below, a number of biochemical abnormalities have been discovered in muscular dystrophy, both in the affected muscles and in the body fluids. As yet, however, it has not been demonstrated that any of these changes are specific for the disease and nothing is known of their relationship to the genetic aberration. It is hoped that further studies, especially in the early stages of the disease, will elucidate the hierarchy of biochemical changes in the diseased muscle and throw light on the basic functional or structural abnormalities caused by the responsible gene.

One of the earliest discovered characteristics, and one which has been extensively confirmed and studied by many workers, is a marked increase in creatine excretion, together with a decrease in urinary creatinine. Thus, to quote from a recent paper by McGeer, McGeer, Miller, Derry \& Nichol (1962), affected boys excreted daily on the average $15.2 \mathrm{mg}$ creatine and $10.4 \mathrm{mg}$ creatinine/ $\mathrm{kg}$ body-weight: the normal values were $8.1 \mathrm{mg}$ and $23.8 \mathrm{mg}$ respectively. (These workers, incidentally, found little or no difference in the rate of excretion of 5 -aminoimidazole-4-carboxamide.) There is a rise also in serum creatine in the disease and a decreased creatine tolerance can be demonstrated. Serum creatinine tends to be low. The marked creatinuria led to much speculation on the possibility of muscular dystrophy's being due to a disturbance of creatine metabolism. There were claims, now largely abandoned, that glycine (a creatine precursor) improved the condition of patients. However, it now seems highly probable that the alterations in the quantities of creatine and creatinine excreted are merely a consequence of the reduction in muscle mass resulting from the disease. Provided the liver and certain other tissues continue to produce normal quantities of creatine, the changes in the excretion pattern can be predicted.

Abnormalities in the urinary excretion of amino acids have been reported by a number of workers. Hurley \& Williams (I955), found greater amounts of taurine and leucine and possibly also of threonine, valine and arginine. Excretion of glycine, alanine, serine and citrulline was normal. Blahd, Bloom \& Drell (1955) found in qualitative studies that muscular-dystrophy patients and their mothers excreted a 
larger variety of amino acids than normal people. Konieczny, Noworytko \& SarneckaKeller ( $195^{8}$ ) detected arginine, threonine and proline in the urine of patients but not of normal people; the patients excreted also increased amounts of other amino acids and peptides. It is an obvious possibility, though by no means proved, that all such increases in amino acid excretion result from protein breakdown associated with muscle wasting.

Danowski and co-workers (Danowski, Wirth, Leinberger, Randall \& Peters, 1956; Danowski, Bastiani, McWilliams, Mateer \& Greenman, 1956; Danowski, Gillespie, Egan, Mateer \& Leinberger, 1956) have made extensive analyses of body fluids in juvenile muscular dystrophy. They report small but significant increases in serum levels of inorganic phosphate and calcium, and a decrease in those of chloride and cholesterol. (The decrease in cholesterol content has been confirmed by others.) No change was observed in the levels of total carbon dioxide, sodium, potassium, total protein, albumin and globulin in the serum, or in those of the non-protein nitrogen and glucose of whole blood. Serum corticoids and excretion of urinary gonadotrophin and $\mathrm{I} 7$-ketosteroids were also normal; there was, however, in some cases, an unusually high level of protein-bound iodine in the plasma. Insulin evoked a normal blood sugar response but subnormal decreases in serum inorganic phosphate and potassium. The degree of hyperglycaemia after adrenaline injection was less than normal.

The presence of ribose in the urine of muscular-dystrophy patients, reported some years ago (Minot, Frank \& Dziewiatkowski, I949), has been shown by several workers, e.g. Walton \& Latner (1954), to be neither a consistent nor specific finding in muscular dystrophy.

A few workers (e.g. Oppenheimer, Shulman, Roberts \& Milhorat, 1959) have made electrophoretic studies on plasma proteins in the disease, but the reported changes (the most consistent being an increase in $\alpha_{2}$-globulin) have been found also in other muscle diseases.

Considerable interest has been taken in recent years in the increase in activity of certain plasma enzymes in muscular dystrophy; these studies were initiated by the observation of Sibley \& Lehninger ( 1949 ) that the level of serum aldolase was raised in the disease. Subsequent work by various authors has shown increases also in lactate dehydrogenase, glutamate-oxaloacetate transaminase, $\alpha$-glucan phosphorylase, phosphoglucomutase, glucosephosphate isomerase and creatine kinase. In contrast, some enzymes, e.g. isocitrate dehydrogenase and acid and alkaline phosphatases, show normal activity. None of these increases is absolutely specific for muscular dystrophy. In general the changes are much more marked in the juvenile (Duchenne) form of the disease, particularly in the early stages. In fact, they may be present to a marked degree long before the disease is clinically evident, perhaps even from birth or before. It should be pointed out that, although the activities of serum enzymes may increase as much as a hundredfold, they are still very minute compared with the corresponding activities in muscle. Even though the rate of removal of plasma enzymes is probably very high (cf. Wróblewski \& LaDue, I955), it is evident that the leakage from the tissue is a very slow process. 
This leakage of enzymes from the muscle is generally presumed to be due to an increase in the permeability of the sarcolemma; probably one has to take into account also leakage due to rupture of the fibres. It is of interest that Zierler (1958) found in vitro a probable increase in the rate of leakage of aldolase from the muscle of mice with hereditary muscular dystrophy. The escape rate, however, was probably much greater than that which occurs in vivo. He showed also that the rate of leakage from normal muscle could be readily increased by a number of factors, such as glucose lack or high concentration of potassium in the medium. There is clearly, as yet, no reason to suppose that muscle-membrane changes are the cause of the muscle degeneration in dystrophy. On the other hand, the very early rise in the levels of serum enzymes and also the fact that smaller rises have been observed in genetic carriers of muscular dystrophy (Dreyfus, Schapira \& Demos, 1960) suggest that membrane changes may be among the more fundamental alterations in the diseased muscle.

The most direct approach to the understanding of muscular dystrophy is, of course, by study of the diseased muscle itself, its chemical composition and enzymic activities. Quantitative work of this nature must take into account the large, nonspecific, increase in fibrous tissue and sometimes of fat. Comparisons of normal and diseased muscle on the basis of weight alone will obviously be misleading. A suitable reference base must be chosen which will make possible valid comparisons of concentrations or activities in normal and dystrophic muscle cells; much earlier work was vitiated by the failure to provide this reference base. Many workers now compare results on the basis of 'non-collagen nitrogen' which appears to be a reasonably satisfactory solution to this problem; it is determined usually as the portion of the tissue nitrogen soluble in dilute alkali.

Up till now the activities of only a score or so of enzymes have been studied in dystrophic muscle. The most extensive study has been that of Dreyfus, Schapira, Schapira \& Demos (1956). They found that many specimens of dystrophic muscle had very low glycolytic activity (average, about one-quarter normal). Assays of individual enzymes showed low levels of $\alpha$-glucan phosphorylase, phosphoglucomutase and aldolase. On the other hand, levels of cytochrome oxidase, succinate dehydrogenase, aconitase, fumarase and transaminases were not significantly different from normal. The magnitude of the changes paralleled the state of progress of the disease. However, similar changes were found in denervation atrophy of muscle. Vignos \& Lefkowitz (1959) found a low rate of glycolysis in the juvenile but not in the adult form of muscular dystrophy. They also found a lowered creatine kinase and adenosine triphosphatase activity and a decrease in myosin content.

The decreased activity of certain glycolytic enzymes in diseased muscle could obviously result from the slow leakage of these enzymes into the blood, as mentioned above. The enzymes showing a decrease are ones believed to exist free in the sarcoplasm and are therefore suitably placed to pass out of the cells if the membrane becomes more permeable or is ruptured. On the other hand, succinate dehydrogenase and cytochrome oxidase are known to be closely associated with cell particles and hence would be less likely to leave the cells. Such an explanation cannot be 
extended to all the enzymes studied since, in many instances, the intracellular localization in skeletal muscle is not known. Moreover, the content of lactate dehydrogenase, which is considered to be a sarcoplasmic enzyme and shows a rise in the plasma in muscular dystrophy, is not decreased in dystrophic muscle (Ronzoni, Berg \& Landau, I96I). It is of interest that Wieme \& Lauryssens (I962) have reported differences in the lactate dehydrogenase isoenzyme pattern of normal and dystrophic muscle. Ronzoni et al. (196I) reported also a normal hexokinase activity in dystrophic muscle. Factors other than attachment to cell bodies, such as molecular size and charge will be expected to influence the escape of enzymes from the fibres. Also, it must be remembered that muscle enzymes, in common with most body proteins, are in a state of continual turnover and nothing is known of the mechanisms which normally maintain constant levels of enzymes, and how these levels would respond if enzymes leaked out of the cells.

Another enzyme which displays a marked fall in activity in human muscular dystrophic muscle is AMP deaminase (Pennington, 1962). Cell fractionation studies carried out so far have not found this enzyme to be localized in any one fraction. Moreover, serums from a number of patients with muscular dystrophy have shown no rise in the activity of this enzyme (Pennington, unpublished).

Still fewer instances of increased enzyme activity in human dystrophic muscle have been reported. In hereditary myopathy in the mouse there is an increase in the activity of cathepsin (Weinstock, Epstein \& Milhorat, 1958) and of certain other hydrolytic enzymes (Zalkin, Tappel, Desai, Caldwell \& Peterson, I961). Cathepsin activity in human dystrophic muscle was found to be very variable but there appeared to be, on the average, an increased level (Pennington, 1962). In dystrophy in the mouse the results of protein turnover studies (Simon, Lessell, Gross \& Milhorat, 1958) show that the muscle degeneration is associated with an increased rate of protein breakdown rather than decreased protein synthesis; the elevated cathepsin activity may be the immediate cause. It remains to be proved whether this finding is true also of human dystrophic muscle.

An interesting marked increase in the activity of a number of NADP-linked dehydrogenases, particularly glucose-6-phosphate dehydrogenase, in dystrophic mouse muscle has been reported (McCaman, I 960). No similar studies on human muscle have yet appeared. It should be mentioned, however, that Rubenstein \& Smith (1962) have recently demonstrated that macrophages found in necrotic lesions in several tissues contained high levels of NADP-linked enzymes. It seems possible that the elevation observed in dystrophic muscle may be a result of invasion by macrophages. Most workers agree that phagocytosis occurs in dystrophic muscle.

Histochemical studies on human dystrophic muscle have indicated the presence of increased quantities of certain dephosphorylating enzymes, in particular 5-nucleotidase (Golarz, Bourne \& Richardson, I96I). This enzyme, however, was confined largely to the connective tissue, which is present in greatly increased amounts in the diseased muscle. In fact, the authors speculated that the disease may originate in the connective tissue, but there is no good evidence for this suggestion. The marked 
increase in 5-nucleotidase activity in dystrophic muscle has been confirmed by quantitative determination (Pennington, 1962).

Studies on the chemical composition of dystrophic muscle (Horvath, Berg, Cummings \& Shy, 1955) have shown that there is a decreased amount of potassium and an increased amount of sodium present, a result not unexpected if there are abnormalities in the cell membrane. Several workers (e.g. Hughes, I96I) have reported a fall in myoglobin concentration in the diseased muscle.

To conclude, much less information is available on the biochemistry of human muscular dystrophy than on vitamin $\mathrm{E}$ deficiency. The fact that the same tissue is affected in both these conditions is, of course, no reason to suppose that the fundamental causes are in any way related. Comparison of the available biochemical data, in fact, makes it seem very unlikely that any of the more common human muscular dystrophies are caused by genetic defects in the metabolism of vitamin E. However, it is reasonable to suppose that the process of muscle degeneration, whatever the cause, has many common features; consequently, research in these two fields may be of mutual benefit.

\section{REFERENCES}

Blahd, W. H., Bloom, A. \& Drell, W. (1955). Proc. Soc. exp. Biol., N.Y., 9o, 7o4.

Danowski, T. S., Bastiani, R. M., McWilliams, F. D., Mateer, F. M. \& Greenman, L. (1956). Amer. $F$. Dis. Child. 9I, 356.

Danowski, T. S., Gillespie, H. K., Egan, T. J., Mateer, F. M. \& Leinberger, M. H. (1956). Amer. F. Dis. Child. 91, 429.

Danowski, T. S., Wirth, P. M., Leinberger, M. H., Randall, L. A. \& Peters, J. H. (1956). Amer. F. Dis. Child. 9I, 346.

Dreyfus, J.-C., Schapira, G. \& Demos, J. (1960). Rev. Franc. d'Et. clin. biol. 5, 384.

Dreyfus, J.-C., Schapira, G., Schapira, F. \& Demos, J. (1956). Clin. chim. Acta, r, 434 -

Golarz, N., Bourne, G. H. \& Richardson, H. D. (1961). F. Histochem. Cytochem. 9, 132.

Horvath, B., Berg, L., Cummings, D. J. \& Shy, G. M. (1955). F. appl. Physiol. 8, 22.

Hughes, B. P. (196r). Clin. chim. Acta, 6, 794.

Hurley, K. E. \& Williams, R. J. (I955). Arch. Biochem. Biophys, 54, 384.

Konieczny, L., Noworytko, J. \& Sarnecka-Keller, M. (1958). Arch. polon. méd. interne, 28, I 579.

McCaman, M. W. (1960). Science, 132,621.

McGeer, E. G., McGeer, P. L., Miller, J. R., Derry, D. \& Nichol, C. (1962). Canad. F. Biochem. Physiol. 40, $\mathrm{I}_{3}$.

Minot, A. S., Frank, H. \& Dziewiatkowski, D. (1949). Arch. Biochem. 20, 394.

Oppenheimer, H., Shulman, S., Roberts, S. \& Milhorat, A. T. (1959). Proc. Soc. exp. Biol., N.Y., 100, 564 .

Pennington, R. J. (1962). Proc. Ass. clin. Biochem. 2, I7.

Ronzoni, E., Berg, L. \& Landau, W. (1961). Res. Publ. Ass. nerv. ment. Dis, 38, 721.

Rubenstein, L. J. \& Smith, B. (1962). Nature, Lond., 193, 895.

Sibley, J. A. \& Lehninger, A. L. (1949). F. nat. Cancer Inst. 9, 303.

Simon, E. J., Lessell, I. M., Gross, C. S. \& Milhorat, A. T. (1958). Fed. Proc. 17, 3 I .

Vignos, P. J. \& Lefkowitz, M. (1959). Y. clin. Invest. 38, 873.

Walton, J. N. \& Latner, A. L. (1954). Arch. Neurol. Psychiat., Chicago, 72, 362.

Weinstock, I. M., Epstein, S. \& Milhorat, A. T. (1958). Proc. Soc. exp. Biol., N.Y., 99, 272.

Wieme, R. J. \& Lauryssens, M. J. (1962). Lancet, i, 433.

Wróblewski, F. \& LaDue, J. S. (1955). Proc. Soc. exp. Biol., N.Y., 9o, 2 10.

Zalkin, H., Tappel, A. L., Desai, I., Caldwell, K. \& Peterson, D. W. (I96r). Fed. Proc. 20, 303.

Zierler, K. L. (1958). Fohns Hopk. Hosp. Bull. ro2, 17. 